\title{
A Systematic Literature Review on Immigrants' Motivation for ICT Adoption and Use
}

Bhanu Bhakta Acharya, University of Ottawa, Department of Communication, Ontario, Canada

\section{ABSTRACT}

Several studies demonstrate that immigrants use computers and the Internet more than non-immigrants or earlier immigrants. What motivates immigrants to use information and communication technology (ICT)? What are the factors that influence immigrants' ICT behaviors? For this study, the author chose 20 peer-reviewed articles published between 2001 and 2015 to study immigrants' motivations for ICT adoption and use. The following article will discuss two motives for immigrants' ICT use, as well as identify seven factors influencing adoption, non-adoption, use, and non-use.

\section{KEYWORDS}

Digital Divide, Immigrant, Influence Factors, Information and Communication Technology, Motivation, Systematic Literature Review, Technology Adoption Model, Theory of Reasoned Action

\section{INTRODUCTION}

The Merriam-Webster dictionary defines immigration as: "Entering and usually becoming established ... to come into a country of which one is not a native for permanent residence." This type of movement—often to a more developed countryhas become a global phenomenon. There are several socio-economic and sociopolitical reasons to migrate from a home country to a host country. These include poverty, unemployment, conflicts, threats, and political captivity. However, leaving a community known since birth and adjusting to a new environment can be challenging 
for immigrants. On one hand, immigrants feel disconnected and isolated from the friends and family that they have left behind. On the other hand, there is a lack of strong networks with people in their new community. Restricted communication by a limited knowledge of the host country's language may cause feelings of loss.

Several studies assessing immigrants' struggles in adjusting to the host country's environment have identified that ICTs - mainly computers and the internet — play pivotal roles in the successful resettlement of immigrants. By using ICTs, immigrants can:

- Reconnect and maintain sociocultural networks back home (Bacigalupe \& Càmara, 2012; Benitez, 2006; Chen, 2010)

- Familiarize themselves with and adjust to a new environment (Benitez, 2006; Kabbar \& Crump, 2006; Khvorostianov, Elias, \& Nimrod, 2011)

- Explore information and provide various support services (Alam \& Imran, 2015; Barth \& Veit, 2011; Peeters \& d'Haenens, 2005)

- Retrieve health information (Bacigalupe, \& Cámara, 2012; Mikal, \& Woodfield, 2015; Selsky, Luta, Noone, Huerta, \& Mandelblatt, 2013)

- Enhance children's education (Kabbar, \& Crump, 2006, 2007; Tripp, 2010)

- Entertain elderly people in their leisure time (Khvorostianov et al., 2011)

Studies have noticed different purposes of ICT adoption and use by immigrants in different parts of the world.

Several studies indicate that limited income, low-level education, lack of skills, and language barriers cause recent immigrants to have lower rates of access to computers and the internet than the locals (Barth \& Veit, 2011; Chen, 2010; Haight, Quan-Haase, \& Corbett, 2014; Kabbar \& Crump, 2006; Mossberger, Tolbert, Bowen, \& Jimenez, 2012; Tsai, 2006). Ahmed and Veronis (2016), Haight et al. (2014), and Ros (2010) noted that recent immigrants are more likely to suffer from the digital divide - the gap between/ among people in regards to their access, skills, usage of and motivation to computers and the Internet (Heisler, 2008; Nguyen, 2012; Sparks, 2013; Van Dijk, 2012). When they do have access to the Internet, they have higher levels of online activities and interactions. Similarly, Kabbar and Crump (2006, 2007) noted that immigrants view ICTs, particularly the computer and the Internet, positively and want to use them as soon as they have the opportunity. Other scholars, such as Mossberger et al. (2012), argue that some immigrants consciously choose not to adopt and use ICT devices because they fear technological risks or have negative feelings about technology. Different findings lead to important questions, such as: What motivates immigrants to use (or not use) ICTs? What factors influence immigrants' decisions to adopt ICTs?

Immigrants have unique socio-cultural backgrounds. Therefore, they may have different perceptions in regards to ICT adoption and use. Identifying immigrants' 
20 more pages are available in the full version of this document, which may be purchased using the "Add to Cart" button on the product's webpage:

www.igi-global.com/article/a-systematic-literature-review-onimmigrants-motivation-for-ict-adoption-anduse $/ 177857$ ? camid $=4 \mathrm{v} 1$

This title is available in InfoSci-Journals, InfoSci-Journal

Disciplines Computer Science, Security, and Information Technology, InfoSci-Select, InfoSci-Technology Adoption, Ethics, and Human Computer Interaction eJournal Collection. Recommend this product to your librarian: www.igi-global.com/e-resources/libraryrecommendation/?id=2

Related Content

Convergence of Wireless Technologies in Consolidating E-Government Applications in Sub-Saharan Africa

Kelvin Joseph Bwalya, Rensleigh Chris and Ndlovu Mandla (2010). International Journal of ICT Research and Development in Africa (pp. 15-30).

www.igi-global.com/article/convergence-wireless-technologies-consolidatinggovernment/53354?camid=4v1a

Social Networking in Academic Libraries: A State-of-the-Art Review of Web 2.0 Library Applications, Issues, and Concerns

Sudhanshu Joshi (2013). Challenges of Academic Library Management in

Developing Countries (pp. 226-248).

www.igi-global.com/chapter/social-networking-academic-

libraries $/ 77984$ ?camid $=4 \mathrm{v} 1 \mathrm{a}$ 
Managing the Performance of Highly Mobile Skilled Individuals in Hi-Tech

\section{Firms}

Samarendra Kumar Mohanty and P. ArunPrasad (2012). Comparing High

Technology Firms in Developed and Developing Countries: Cluster Growth Initiatives (pp. 167-184).

www.igi-global.com/chapter/managing-performance-highly-mobile-

skilled/65998?camid=4v1a

Mobile Agriculture in South Africa: Implementation Framework, Value-Added Services and Policy Implications

Blessing Mukabeta Maumbe (2010). International Journal of ICT Research and

Development in Africa (pp. 35-59).

www.igi-global.com/article/mobile-agriculture-south-

africa/46099?camid=4v1a 